\title{
Linking and leveraging resources for innovation and growth through collaborative value creation: A study of Indian OSPs
}

\begin{abstract}
How have numerous knowledge-intensive technology-based providers of professional services from emerging economies grown quickly to become dominant global players in their fields? We draw from the collaborative value creation perspective to develop a conceptual model which argues that professional service providers from emerging economies pursue high quality collaborations with clients and their networks to overcome their resource constraints in sustaining their international growth. We test our model on a sample of offshore service providers (OSPs) from India which have experienced rapid international growth. The results show that OSPs develop and maintain high quality relationships with clients and their networks in the co-creation of innovative and customised business solutions for their clients. High quality collaborations allow OSPs to gain access to and exploit network resources. The research supplements Mathews (2006) internationalisation framework with the collaborative value creation theoretical perspective in explaining the resource linking-leveraging processes specific to service EMNEs. The theoretical and practical implications of the findings for the internationalisation of professional service providers from emerging economies in general are fully discussed.
\end{abstract}

Keywords: relationship quality, innovation, information technology services, offshore service providers, collaborative value creation, emerging economy, India.

\section{Please cite this paper as}

Chadee, D., Sharma, R. R., \& Roxas, B. (2017). Linking and leveraging resources for innovation and growth through collaborative value creation: A study of indian osps. Asia Pacific Journal of Management (34), 777-797. doi: https://doi.org/10.1007/s10490-016-9485-9 
Firms from emerging economies have been found to face a number of disadvantages when entering into international markets. They suffer from the liability of foreignness (Gaur, Kumar, \& Singh, 2014; Zaheer, 1995), the liability of origin (Bartlett, \& Ghoshal, 2000; Ramachandran, \& Pant, 2010), lack of legitimacy (Elango, \& Pattnaik, 2007; Madhok, \& Keyhani, 2012; Sauvant, Maschek, \& McAllister, 2009) and capacity and capability constraints (Ramachandran, \& Pant, 2010). Despite these disadvantages, the UNCTAD (2014) reports that the last two decades have experienced the fastest growth in the internationalisation of multinationals from emerging markets (EMNEs). India is a case in point which exemplifies this trend through the rapid rise in the number of offshore service providers (OSPs) in the field of information and communication technology services to clients worldwide. OSPs such as Infosys, TCS, HCL and Wipro have developed quickly into large conglomerates to compete successfully against their western counterparts and become global leaders in their fields. For example, Infosys which is widely recognised as a global leader in consulting, technology and outsourcing solutions, started in 1981 by seven young entrepreneurs in Pune, India, with a mere US\$250 as capital. As of FY 2016, Infosys had an annual turnover of US\$ 9.5 billion and a workforce of more than 194000 employees in more than 50 countries (www.infosys.com/about). The emergence and rapid growth of this new breed of EMNEs raise important questions about how these firms enter and quickly succeed in international markets despite the inherent limitations which they face by virtue of being from emerging economies.

Traditional internationalisation theories are deficient in explaining this new phenomenon (Gaur et al., 2014; Meyer, \& Thaijongrak, 2013; Nandakumar, Purkayastha, \& Kumar, 2016; Ramamurti, 2012) because they are based mostly on the experience of MNEs from advanced industrialised economies. However, EMNEs come from relatively weaker institutional environments and they internationalise to avoid home country challenges (Cuervo- 
Cazurra, 2016; Kumar, Mudambi, \& Gray, 2013). A recent notable attempt in providing an alternate explanation of the rapid internationalisation of EMNEs is the linking-leveraginglearning (LLL) framework (Mathews, 2006a; Mathews, 2006b). The main tenant of the LLL internationalisation framework is that through the process of continuous learning, EMNEs develop high quality partnerships (linking) with relevant stakeholders for the purposes of accessing network resources (leveraging) to create new bundles of resources which allow them to compete successfully in international markets (Mathews, 2006a). A small but growing number of research which applies the LLL framework has since emerged to explain the conduct and performance of EMNEs from India (Chittoor, Sarkar, Ray, \& Aulakh, 2009; Thite, Wilkinson, Budhwar, \& Mathews, 2016) and China (Cardoza, \& Fornes, 2011; Hao, \& Mathews, 2015) with a particular focus on manufacturing EMNEs (Hao, \& Mathews, 2015; Thite et al., 2016). Although these studies provide new insights into how the linkingleveraging-learning processes explain the rapid internationalisation of EMNEs, our understanding of the new breed of knowledge-intensive technology-based firms such as OSPs remains fragmented. Service firms are different from manufacturing firms (Chadee, \& Mattson, 1998) due to the intangibility, inseparability, heterogeneity, and perishability (Zeithaml, Parasuraman, \& Berry, 1985) of services, particularly in an international context where service providers and their consumers are separated by time and distance. OSPs, for instance, enter projects with people, knowledge and information only in providing a variety of highly customised IT support and consultancy services to clients globally. The rapid pace of technological change means that OSPs need to constantly innovate in order not to become obsolete. This is because the routines and processes of the services which they provide evolve over time as new technology becomes available. . Thus, an important question arises as to how OSPs from emerging economies which suffer from capability and capacity constraints 
(Ramachandran, \& Pant, 2010) constantly innovate to remain competitive and grow? We address this question by supplementing Mathews (2006a) internationalisation framework with the collaborative value creation perspective (Moeller 2013) in explaining the linkingleveraging processes specific to knowledge-intensive and technology based EMNEs such as OSPs for which innovation is a critical element of their competitive advantage. This research argues that OSPs sustain their innovation and grow by linking and leveraging resources through the development and maintenance of high quality relationships with their clients and their wider networks.

Accordingly, this paper assesses the role of the quality of relationships between OSPs and their partners in invigorating their innovation and growth through collaborative value creation. In doing so, the paper makes several contributions to the literature on EMNEs. Firstly, the paper extends the application of Mathews (2006a) internationalisation framework to professional service providers. To our knowledge, Mathews (2006a) internationalisation framework has so far been predominantly applied to manufacturing EMNEs and the extension to service EMNEs contributes to its generalisation. Secondly, the paper makes a theoretical contribution by drawing from the collaborative value creation theoretical perspective in articulating Mathews (2006a) linking and leveraging concepts in the context of professional service providers. Thirdly, the paper highlights the critical role of relationship quality in facilitating resource linking and leveraging for sustaining innovation and growth of OSPs. Lastly, the paper contributes to the small but growing literature on the conduct and performance of an increasing number of EMNEs in general and those which are technology and knowledge based in particular. 


\section{Theoretical considerations and hypotheses}

Innovation is critical for the growth of knowledge based industries such as OSPs because of the short technology life cycle and service routines and processes evolve over time. Through innovation, OSPs can constantly upgrade their existing services or introduce new processes which add value to their clients' businesses. Innovation is the outcome of successful strategies, investment, and relationships which companies actively seek and develop in the market (Conte, \& Vivarelli, 2013; Leiponen, 2012). However, an innovation strategy by itself does not necessarily enhance a firm's performance. Rather, it is the eventual successful commercialisation and application of innovative products and processes which improve the efficiency and profitability of firms. Thus, this research explicitly distinguishes between innovation strategy and innovation outcomes at the firm level according to the Oslo Manual (OECD, 2005). This distinction is important in the context of firms from emerging economies where the environment for innovation may be under developed and where firms often lack the necessary resources for undertaking R\&D activities which lead to new or substantially improved products and services despite having a well-developed and articulated innovation strategies. Furthermore, the high rate of failure often associated with R\&D projects also raises questions about whether innovation strategy alone at the firm level constitutes an appropriate indicator of innovativeness (Damanpour, \& Aravind, 2011). While a firm's innovation strategy is important, what is more important from a performance perspective, is the successful implementation of the strategy which leads to the introduction of new or substantially improved products and services that attract clients (Lewin, Massini, \& Peeters, 2009). But how do service providers from emerging economies where the institutional environment is not necessarily conducive to innovation activities constantly innovate to create value for their clients? 
To address this question, we draw from the value co-creation perspective (Vargo, 2008) and its extension (Moeller, Ciuchita, Mahr, Odekerken-Schroder, \& Fassnacht, 2013) to illustrate how OSPs are able to innovate and remain competitive by collaborating closely with their clients. Collaborative value creation (Moeller et al., 2013) is based on the notion that in the context where services cannot be tested until realised, as is the case with OSPs, service providers and their clients stand to benefit mutually from close collaboration. Collaborative value creation encourages the active participation of clients (service consumers) in the design and delivery of innovative customised services which meet their performance objectives and greatly reduces the risk of service delivery failure. Client firms possess unique tangible and intangible resources which when combined with the resources of the service provider (OSPs) can reduce the risk of failure and the cost of innovation (Franke, \& Schreier, 2010). Thus, both service providers (OSPs) and their clients are more likely to fully realise their respective strategies and meet their own performance objectives by collaborating with each other in the design and delivery of customised services. The success of collaborative value creation relies on the development and maintenance of effective relationships between service providers, their clients and the wider industry networks (Moeller et al., 2013). According to the relational capital perspective (Kale, Singh, \& Permutter, 2000), high quality relationships based on high levels of trust, understanding and commitment provide network members with insights into each other's resource capability and business objectives. High quality relationships also create opportunities for network members to either jointly or independently leverage network resources thereby allowing them to overcome their capacity and capability constraints and enjoy higher innovation rates.

We illustrate a simple example of value co-creation in the IT services offshoring sector in Figure 1 where two typical OSPs; A and B, service four different clients each. OSPA services 
clients $\mathrm{A}_{1}, \mathrm{~A}_{2}, \mathrm{~A}_{3}$ and $\mathrm{C}_{4}$ while $\mathrm{OSP}_{\mathrm{B}}$ services clients $\mathrm{B}_{1}, \mathrm{~B}_{2}, \mathrm{~B}_{3}$ and $\mathrm{C}_{4}$. The solid arrows indicate two way knowledge sharing and learning between the OSPs and their clients in the coproduction and delivery of customised services. The dotted lines indicate that different clients and the two OSPs can also learn from each other through collaboration and the sharing of information. It is not uncommon for different OSPs to service a particular client, albeit in the provision of different or complementary services which require highly specialised skills. This is shown in Figure 1 where client $\mathrm{C}_{4}$ is serviced by both $\mathrm{OSP}_{\mathrm{A}}$ and $\mathrm{OSP}_{\mathrm{B}}$ which suggests that the information exchange boundary between the two OSPs is permeable. Thus, value cocreation in the IT services sector implicitly involves OSPs learning from each other as well as from their clients because they are linked to each other in various, complex and, sometimes invisible patterns of relationships (Johanson, \& Vahlne, 2011). OSPs which follow the deliberate strategy of seeking out compatible clients with whom they can develop and maintain high quality relationships are more likely to be successful in overcoming their resource constraints and sustaining their innovation by linking and leveraging network resources.

\section{* Insert Figure 1 here*}

\section{Collaborative innovation strategy, innovation outcomes and performance}

Collaborative innovation strategy (CIS) refers to the strategic orientation of a firm in proactively and continually collaborating with its stakeholders for the development and commercialisation of new or improved products, services and processes so as to stay ahead of its competitors. A firm's stakeholders include its clients, suppliers, finance institutions, distributors, and the broader network of businesses which directly or indirectly support its activities. A firm's strategic stance towards collaboration for innovation articulates in broad terms its strategy in searching, managing and leveraging internal and external resources in 
order to exploit emerging business opportunities. Firms have been found to achieve superior performance when there is a fit between their strategic orientations, resources, and business opportunities (Bowen, Rostami, \& Steel, 2010; Crossan, \& Apaydin, 2010; Slater, Olson, \& Hult, 2006). CIS is particularly beneficial for the performance of knowledge based firms such as OSPs where services cannot be tested until realised. In such cases collaboration with clients greatly reduces the risks of failure and improves performance. CIS can also enhance the performance of OSPs by providing access to valuable tacit knowledge about the needs of clients and their resources. Lastly a well-developed CIS can also articulate the sharing of the costs of innovation, particularly in cases when innovation activities require excessive amounts of R\&D expenditures which are beyond the capacity of any single firm. Through collaboration and $R \& D$ cost sharing, OSPs can benefit from innovation activities which would otherwise not take place due prohibitively high costs. Hence,

H1: Collaborative innovation strategy (CIS) contributes positively to the growth of OSPs.

Innovation can occur either on an ad-hoc and opportunistic basis or can be strategically planned based on strong R\&D orientation of the firm (Leiponen, 2012). OSPs which take a strategic and planned approach to innovation are more likely to achieve their innovation performance outcomes (Conte, \& Vivarelli, 2013) such as the introduction of new and improved services and processes which add value to clients' businesses. A collaborative approach to innovation is more likely to lead to the desired innovation outcomes bacause OSPs and their clients work closely together in the design and delivery of customised solutions for clients. Close collaboration between OSPs and their clients strengthens the capability of OSPs to be flexible and resilient in the midst of a complex and dynamic global business environment (Melia, Perez, \& Dobon, 2010) thereby reducing the risk of service delivery failure. CIS also leads to 
increased innovation outcomes through the exploitation of organisational synergies embedded in organisational capabilities and operational routines (Melia et al., 2010) of OSPs and their clients. Access to network resources extend the capabilities of OSPs to operate beyond their own resource frontiers and deliver innovation outcomes which would otherwise not be possible. OSPs with well-developed CIS are also more likely to have clear plans of how to achieve their IO objectives given their own resources and their clients' resources which they have access to. The capability to leverage and connect different resources from clients in order to create unique bundles of resources to address specific needs of clients enhances the success rate for innovation. Hence,

H2: Collaborative innovation strategy (CIS) contributes positively to innovation outcomes (IO) of OSPs.

The overall performance and growth of knowledge-intensive and technology organisations depend crucially on their ability to sustain their innovation (Kumar et al., 2013). This is due to the rapid pace of technological change and the ever shortening of technology life cycles. In such an environment where technology quickly becomes obsolete technology-based organisations such as OSPs need to constantly innovate in order to sustain their competitiveness and overall growth (Holtzman, 2014). Thus OSPs which are more innovative as indicated by their ability in constantly introducing new or substantially improved services are more likely to experience overall superior growth for the following reasons. Firstly, collaborative value creation (Moeller et al., 2013) for innovation leads to higher rates of innovation at overall lower costs, thereby improving overall financial performance and growth of the firm. Collaborative value creation through the sharing of $R \& D$ costs also allows OSPs to benefit from higher returns on investments in innovation related projects as a result of the risks of failure being shared with clients. Secondly, the introduction of new or substantially improved services and 
processes can lead to improvements in the productivity, profitability and market leadership of OSPs. Thirdly, the ability of OSPs to continuously create new and more efficient services and processes which give their clients a competitive edge not only leads to improved retention of existing customers but also leads to growth in the client base through positive referrals from existing clients (Holzweber, Mattsson, Chadee, \& Raman, 2012; Stuart, Hoang, \& Hybels, 1999). Lewin et al. (2009) found that the track records of OSPs in offering their clients improved or new business solutions is a major consideration by clients when selecting appropriate OSPs to partner with. The overall discussion suggests that higher innovation outcomes result in overall superior performance through improved efficiency, productivity, retention of existing clients and expansion of the overall client base. Hence,

H3: Innovation outcomes (IO) contribute positively to the growth of OSPs.

\section{Mediating role of relationship quality}

In order to explain the mediating role of relationship quality on the CIS-IO relationship, we first explore the CIS-RQ and RQ-IO relationships (see figure 2). As pointed out earlier, an innovation strategy (CIS) by itself does not necessarily lead to innovation outcomes (IO) such as improved or new services and processes. This is because EMNEs are often constrained in the implementation of their innovation strategies by a lack capacity and capability (Ramachandran, \& Pant, 2010) and the institutional environment which is often not conducive to innovation. In order to overcome such constraints, OSPs in India have been found to develop strong relationships with their clients with whom they collaborate actively in value co-creation for innovation related activities. For example, HCL, which has operations in more than 31 countries and market capitalization estimated at US\$ 15 billion in 2015, attributes its rapid growth to "creating value through relationships with clients" and "the belief in taking every 
relationship beyond the contract by putting our own skin in the game through collaboration, applied innovation and new generation partnership models that put our customers' interests above all else". HCL further emphasizes that "while we pride our eye to detail in constructing robust contracts with clients, we realize that only a Relationship Beyond the Contract can capture what will change tomorrow". (http://www.hcltech.com/about-us/about-hcltechnologies). Similarly, WIPRO which has established itself as a global leader in its field with more than 165000 employees in 75 countries, emphasises that "Strategic Partnerships are one of the core pillars of business objectives that help our customers Do Business Better. We have a 360 degree relationship with our alliance partners. As a vendor, partner and a customer, the Wipro Winning Together approach is aimed at delivering unparalleled value to clients." (http://www.wipro.com/about-Wipro/).

Collaborative innovation strategy considers clients as integral contributors in the innovation value creation process. Clients engage in joint innovation activities with OSPs and or provide access to unique resources which they possess to increase the fit of the innovation with their own preferences (Franke, \& Schreier, 2010). For this reason, there is a mutual realisation from OSPs and their clients that developing and maintaining effective relationships is critical for successful value co-creation in innovation (Kühne, Gellynck, \& Weaver, 2013; Roy, Sivakumar, \& Wilkinson, 2004). OSPs and their clients choose each other carefully based on whether there are strong synergies between their organisations which can be exploited for mutual gains; including relational synergies. Because CIS is a deliberate pursuit by OSPs for gaining access to network resources, the nurturing of relationships becomes an integral part of the process of successfully implementing CIS. Hence,

H4: Collaborative innovation strategy (CIS) is positively related to OSP-client relationship quality (RQ). 
Next, we explore how high quality relationships between OSPs and their clients (RQ) enhance innovation outcomes (IO). Firstly, effective OSP-client relationships can result in the coproduction of high quality customised services by exploiting the advantages related to relational capital, co-specialization and mutual learning (Kale et al., 2000; Lahiri, \& Kedia, 2009; Lee, 2001). High quality OSP-client relationships can facilitate learning and knowledge sharing across boundaries (Adler, 2002; Kale et al., 2000) which can accelerate the successful completion of innovative services and processes. Secondly, OSPs can leverage their clients' local knowledge to assist them navigate the complex regulatory, administrative and legal environments and overcome the institutional barriers in relation to the introduction of new services (Peng, Sunny Li, Pinkham, \& Hao, 2009). Thirdly, the very nature of the complexity involved in 'outside service consultants' (OSPs) coming into an organisation and working on premises for an extended period of time often dealing with sensitive information requires a high level of trust on both sides. Information exchange and coordination between clients and vendors are essential in co-creating products and services as per the clients' needs and expectations (Holzweber et al., 2012; Vargo, \& Lusch, 2004). Hence, effective OSP-client relationships help smooth information exchange processes and improve the quality and speed of service delivery which can facilitate the realisation of the innovation strategies. Fourthly, effective OSP-client relationships allow clients to provide OSPs with valuable and constructive feedback on ways to improve their services, processes and the quality and speed of service delivery which can facilitate the realisation of the innovation strategies (Holzweber et al., 2012). Constructive feedback allows for greater cooperation between OSPs and their clients which in turn provides greater focus for the implementation of the innovation strategies of OSPs and the introduction of services and processes which meet client's needs and expectations. Lastly, good OSP-client relationship helps to mitigate future uncertainties and 
risks arising out of incompleteness of contracts (Barthelemy, 2003) in relation to innovation activities. The discussion above leads to the following hypothesis:

H5: OSP-client relationship quality (RQ) contributes positively to innovation outcomes (IO) of OSPs.

While developing quality relationships with clients has become an integral part of the overall innovation strategies of OSPs, the question which arises is how does relationship quality (RQ) help OSPs transform their innovation strategies (CIS) into innovation outcomes (IO)?

A small but emerging literature on the importance of relational capital in relation to OSPs specifically (Lahiri, \& Kedia, 2009; Raman, Chadee, Roxas, \& Michailova, 2013) highlights the development and maintenance of high quality relationships with clients as a central element of the growth strategies of OSPs. The quality of OSP-client relationships influence the extent to which clients allow OSPs access to their resources. Clients possess tacit knowledge about their needs and expectations. Such information is critical for OSPs in order to be able to provide customised and innovative solutions to their clients which will sustain their competitiveness in anticipation of their future needs. Clients are more likely to share such information with OSPs when their relationships are strong. Thus, effective OSP-client relationships (RQ) allow OSPs leverage network resources towards the delivery of innovative outcomes for their clients. High quality relationships between OSPs and their clients facilitate the implementation of CIS due to high levels of trust, commitment and knowledge of each other's businesses and resources. RQ provides the mechanism which enables OSPs turn their strategic orientations towards collaborative innovation (CIS) into actual new and improved products and services (IO) which meet the test of their clients. In effect, RQ plays a mediating role in translating CIS into IO. Hence 
H6: OSP-client relationship quality (RQ) mediates the effects of collaborative innovation strategy (CIS) on innovation outcomes (IO) of OSPs.

The conceptual model in Figure 2 shows that the overall performance of OSPs (BG) depends on their ability to continually introduce new or significantly improved services and processes (IO) which add value to their clients' businesses. OSPs sustain their innovation (IO), by developing high quality relationships (RQ) through various linkages with clients and their wider networks to gain access to (leverage) valuable network resources in order to transform their collaborative innovation strategies (CIS) into innovation outcomes (IO).

* Figure 2 about here*

\section{Methods and data}

We test hypotheses $\mathrm{H}_{1}$ to $\mathrm{H}_{6}$ using data from a sample of OSPs in the IT services sector in India. The Indian IT services sector has experienced rapid growth during the last two decades. Various industry reports (Nasscom, 2013, 2015) indicate that the industry's contribution, during the period 1998 to 2015 to the national GDP increased from $1.2 \%$ to $9.5 \%$; and its share of national export revenues increased from $4 \%$ to more than $25 \%$. Further, the industry's revenue was estimated to be approximately USD 146 billion in 2015 and accounted for 55\% global market share. In 2015, the Indian IT services sector employed approximately 3.5 million people directly and provided employment to a further over 10 million people indirectly. Numerous OSPs from India are leading players in the global services offshoring sector and as such, India is widely regarded as the most attractive offshoring destination for IT services (Raman, \& Chadee, 2011; Sethi, \& Gott, 2016).

The data used for hypotheses testing was collected from an online survey of members of Nasscom conducted by the authors. Nasscom which is India's largest association of OSPs, accounts for more than $95 \%$ of the industry's total revenue (Nasscom, 2010). A questionnaire 
was developed and administered online to members of Nasscom to capture various aspects of the behaviour and performance of OSPs. After an initial pilot testing, the final questionnaire was screened and endorsed by Nasscom before being distributed to all 842 members.

A total of 96 questionnaires were returned following two separate reminders at a week's interval. After eliminating incomplete responses, 68 questionnaires were retained for the purposes of analysis. The response rate $(8 \%)$ is deemed reasonable when considering the difficulties associate with primary data collection in developing countries in general and in India specifically (Roy, \& Berger, 2005). The sample consists of OSPs with diverse characteristics in terms of experience, size and nature of business operations. About $60 \%$ of participating OSPs are less than 10 years old, 55\% had more than 1000 employees, 40\% provide software development and application services only and $20 \%$ provide BPO services only, with the rest providing end-to-end services.

\section{Measurement}

This study followed the standard scale development process (Bagozzi, Yi, \& Phillips, 1991; DeVellis, 2012) in developing the measures of the various constructs. This process includes a review of the literature in order to determine the conceptual definitions of the constructs and to develop the relevant measures. The items from the questionnaire and the corresponding constructs are summarised in Table 1. Each construct consists of multiple items as follows:

Collaborative innovation strategy (CIS): This construct refers to the strategic stance of OSPs in proactively collaborating with its stakeholders for the development and commercialisation of new or improved products, services and processes so as to stay ahead of its competitors. Drawing on the work of Ayuso, Rodriguez, Garcia-Castro, and Arino (2011), Melia et al. (2010), and Kumar, Boesso, Favotto, and Menini (2012) five items were adapted 
to describe the CIS of OSPs in the sample. Examples of sample item for CIS, for instance, include: "This company maintains strong networks for collaboration", "This company actively involves clients in design and delivery of customised solutions", "This company uses client connections to acquire resources". All items are measured on a five point Likert type of response scale where $1=$ do not agree with statement at all, $\ldots, 5=$ totally agree with statement.

Relationship quality $(R Q)$ : We measured the quality of relationships between OSPs and their clients by adapting five items from (Lee, 2001). Relationship quality embodies the level of trust, commitment, business understanding and conflict management between the OSPs and their clients (Lee, 2001). Sample items include having common understanding of business objectives between OSPs and their clients, maintaining good and mutually beneficial relationships, and resolving disputes swiftly and amicably. All items for relationship quality are measured on a five point Likert type of response scale where $1=$ do not agree with statement at all, $\ldots$, to $5=$ totally agree with statement.

Innovation outcomes $(I O)$ : Three items were developed to describe the outcomes or outputs of innovation activities undertaken by OSPs. The items are consistent with the Oslo Manual's (OECD, 2005) measurement of innovation outputs and capture the extent to which OSPs introduce actual innovative products, services and processes. Sample item states, "We have introduced new products, services, business models, and practices during the last 2 years"; "we continually improve products, services, business models for our clients"; "we have launched 'first of its kind in the world' products and services for our clients". All items are measured using a binary scale where $1=$ yes and $0=$ no.

Business growth $(B G)$ : Client base retention and expansion is a critical strategic measure of business growth for OSPs. About $70-80 \%$ of the revenue of the leading Indian OSPs come from repeat business with their existing clients (Infosys, 2014; McManus, Li, \& 
Moitra, 2007). Client retention is particularly important for OSPs because they provide services which cannot be tested until realised and client referrals provide testimonials on the quality of their services. Such referrals have been found to be critical in enhancing business performance and growth (Stuart et al., 1999). The expansion of the client base across national boundaries is also critical for OSPs in managing and diversifying political and economic risks and uncertainty from regional markets. Two items were used to capture business growth of OSPs relative to industry benchmarks over a two year period. The first item asks respondents to rate, on a five point scale ( 1 =way below industry average, $\ldots, 5=$ way above industry average), the extent to which their firms have been able to retain their existing clients. Similarly, the second item asks respondents to rate the company's performance relative to the industry in attracting new clients and expanding its client base.

Control variables: In assessing business growth, the study controls for business experience (i.e. number of years of business operation) and firm size (Lahiri, \& Kedia, 2011; Raman et al., 2013). Both variables which are likely to influence the ability of OSPs in retaining existing customers and in attracting new ones can potentially influence their growth.

\section{Mono-method Bias Analysis}

We conducted a common factor analysis as recommended by Harman (1976) as a post-hoc test for mono-methodological bias. As expected, no single factor accounted for more than $50 \%$ of the variance among the relevant items that were used in this study. We also applied Lindell, and Whitney (2001) partial correlation technique using a marker variable called use of technology measured by four items. This construct was established a priori to have no theoretical or conceptual relationship with at least one of the major variables under study (Malhotra, Kim, \& Patil, 2006). This approach suggests that common method variance is 
present if there are significant changes in inter-factor correlations after controlling for the effects of the marker variable (Lindell, \& Whitney, 2001). Using SPSS's partial correlation analysis function, the results of our analysis showed that there were no significant changes among the correlation coefficients of the main constructs of this study when the marker variable was controlled for. The results further suggested that common method bias, per se, could not explain the results of the current study.

\section{Model estimation and results}

This study uses the partial least squares (PLS) approach to structural equation modelling in order to test hypotheses $\mathrm{H}_{1}$ to $\mathrm{H}_{6}$ aided by the software WarpPLS v. 3 (Kock, 2012). SEM using PLS-bootstrapping routine (100 resamples) is a robust technique for model estimation and has the capability to address multi-collinearity, small sample size, few variables and indicators, and non-normal distribution of data (Pulos, \& Rogness, 1995). The characteristics of the current dataset such as small sample size $(n=68)$, few indicators (15), very few latent variables (4), minimum factor loading of .61 and minimum factor inter-correlation of .26, are considered adequate in order to develop and test the alternative structural models with acceptable statistical power (Marcoulides, \& Saunders, 2006).

A two-step structural equation modelling approach was followed in this study which requires development and testing of a measurement model followed by the development and testing of competing structural models (Anderson, \& Gerbing, 1988). A confirmatory factor analysis was first performed to assess whether the items loaded highly and significantly on their a priori latent variables. If the items loaded well on their pre-determined constructs, we consequently examined the constructs' reliability and validity. The results which are summarised in Table 1 show that the pre-determined set up of each construct with its 
corresponding items fits the data well. The items loadings are significant $(\mathrm{P}<.05)$ and the crossloadings to other constructs are substantially lower than the a priori loadings. The indicators of item homogeneity and consistency (i.e. Cronbach $\alpha$ ), scale reliability (i.e. composite reliability coefficient), and construct validity (i.e. Joreskog's $\rho$ ) suggest the satisfactory fit between the data and the pre-determined measurement model. The full collinearity variance inflation factors are lower than the maximum tolerable value of 5 (Hair, Black, Babin, \& Anderson, 2010) which suggest that multi collinearity is not an issue in the measurement model.

The next table, Table 2, shows the descriptive statistics and inter-factor correlations of the variables that were used in the succeeding analysis. The square root values of the average variance extracted (AVEs) by each construct are much higher than the coefficients of correlation between and among constructs which suggest the discriminant validity of the constructs used in this study. Overall, the results of the test of the measurement model-data fit suggested that the constructs used in this study have satisfactory levels of construct validity, internal consistency (i.e., reliability), and convergent as well as discriminant validity.

\section{*Tables 1 \& 2 about here *}

The next step is the development and testing of the structural models in order to test the hypotheses of this study. We developed three structural models in order to examine the nature and extent of relationships of the focal constructs of this study. Model A shows the direct positive and significant effects of CIS on BG which supports $\mathrm{H}_{1}$. This is the baseline model through which we further examined the interactive effects of RQ and IO on BG as shown in Models B and C. Model B is a partial mediation model which shows the direct and significant effects of CIS on IO and RQ, the significant effects of RQ on IO and the significant effects of IO on BG. This model shows that the direct effects of CIS on BG become weak and 
insignificant when IO is taken into account suggesting a full mediating role of IO in the CISBG relationship. This model further suggests that RQ only partially mediates the effects of CIS on IO and that there are other mediating or confounding factors that are unexplained and unaccounted for in the model. Model $\mathrm{C}$ is a full mediation model which shows only the direct and significant effects of CIS on RQ, RQ on IO, and IO on BG. In other words, this model shows that CIS does not have a direct effect on IO. Instead it has an indirect effect through the mediating mechanism of RQ. The parameter estimates for the three models are illustrated in Figure 3.

* Figure 3 about here *

In order to determine which model (i.e. Model B or C) has better explanatory power with respect to the mediating effects of RQ (i.e. whether partial or full mediation), we use the average R-squared (Kock, 2012) and Amato, Esposito-Vinzi, and Tenenhaus (2004) indicator of global goodness of fit. Model B (partial mediation) has higher ARS value and global goodness of fit value compared to Model $\mathrm{C}$ which suggest that the former has stronger explanatory power than the latter (Wetzels, Odekerken-Schröder, \& van Oppen, 2009). The results shown in Model B suggest that RQ plays a partial yet substantial mediating role in explaining the effects of CIS on IO. Some other factors unaccounted for in the model also explain the CIS $\rightarrow$ IO linkage. Both CIS and RQ explain significantly approximately $28 \%$ in the variations of the IO of the sample firms which support $\mathrm{H} 2$ and H5. CIS also significantly explains $70 \%$ of the variations in the level of RQ, thereby supporting H4. IO on the other hand along with experience, explains $46 \%$ of the variations in the level of BG of firms in the sample, a result which supports $\mathrm{H} 3$. The results also offer partial support to H6 such that CIS has both significant direct and indirect effects (i.e. through RQ) on IO suggesting the partial mediating 
role of RQ. Although the baseline model (Model A) shows the strong significant direct effects of CIS on BG, these effects were diminished when the mediating roles of both RQ and IO are taken into account as shown in Model B. These findings suggest that RQ and IO have strategic mediating roles to play in transforming CIS into BG. The Stone-Geisser Q2 values are all nonzero which indicate the acceptable level of predictive validity of Model A (Geisser, 1975; Stone, 1974). The Cohen's $\mathrm{f}^{2}$ values suggest that the effect sizes range from medium to large which indicate that the significant effects are substantially meaningful in explaining the relationships of the constructs in the model (Cohen, 1992).

We further tested the significance of the indirect effects suggested by Model B following Preacher, and Hayes (2008). The results show that the indirect effects (i.e. path passing through CIS $\rightarrow$ RQ $\rightarrow$ IO are significant and have acceptable explanatory power as indicated by the medium to large effect sizes (Cohen, 1992). The foregoing discussion of the results suggests that mediation effects are partially supported by the data. Hence, we can conclude that there is partial support for H6.

*Table 3 about here*

\section{Discussion, implications and conclusions}

This paper investigates the broader question of how EMNEs succeed in international markets by focusing specifically on the experience of a sample of global knowledge-intensive technology-based professional service providers (OSPs) from India. Despite the fact that EMNEs have experienced rapid growth during the last two decades, research on their conduct and performance remains underdeveloped. And, because traditional internationalisation theories are based on the experience of firms from advanced industrialised countries, they are deficient in explaining the rapid internationalisation of EMNEs (Hennart, 2012; Nandakumar 
et al., 2016; Ramamurti, 2012). A notable attempt which departs from traditional internationalisation theories is Mathews (2006a) linking-leveraging-learning framework. Accordingly EMNEs link and leverage resources through a process of continuous learning in order to overcome their resource constraints in successfully entering international markets. Todate, Mathews (2006a) internationalisation framework has been applied mostly in explaining the internationalisation of manufacturing EMNEs. This research contributes to the growing literature on the LLL framework by supplementing it with the collaborative value creation (Moeller et al., 2013) concept in explaining the linking and leveraging processes in the context of professional service providers from emerging economies. The results of this study show that OSPs from India have experienced rapid growth by being able to sustain their innovation through collaborative innovation strategies based on high quality relationships with clients and their networks. High quality relationships help OSPs to realise their innovation strategies by facilitate access to and exploitation of network resources. Successful collaborations with clients and their networks in value creation enable OSP to minimise the risks of failure and to deliver cheaper and faster innovative and customised business solutions to their clients. The ability to sustain their innovations through close collaboration with clients led to improved customer retention and also help attract new customers.

This study makes several distinct contributions as follows. First, this study provides new insights into the relevance and applicability of Mathews (2006a) LLL framework to service firms. The findings of this research provide additional support towards the generalisation of LLL framework in explaining the rapid internationalisation of service firms. Second, the study makes a theoretical contribution by supplementing Mathews (2006a) framework with the collaborative value creation (Moeller et al., 2013) theoretical perspective in explaining the conduct of service providers. The collaborative value creation perspective 
provides new theoretical insights in explaining the resource linking and leveraging behaviour of service EMNEs. The results of this study confirm that OSPs are able to overcome their resource constraints by pursuing high quality collaborations (linking) which allow them to access and exploit (leverage) network resources in realising their growth objectives.

A critical element of effective collaborative value creation is the quality of relationships between collaborators. The third contribution of the study was to conceptualise relationship quality as the mechanism which transforms the innovation strategy of OSPs into innovation outcomes which contribute towards their growth. The results show that high quality relationship between OSPs and their clients partially but significantly mediates the effects of collaborative innovation strategy on innovation outcomes. The results provide empirical support to our contention that relationship quality, which underpin collaborative value creation, help mitigate the risks of failure for both OSPs and their clients by encouraging constant customer feedback and their active participation (Holzweber et al., 2012; Moeller et al., 2013). The findings also suggest that relationship quality fits Barney's (1991) characteristics of resources capable of conferring competitive advantage by being valuable, rare, inimitable and non-substitutable. Relationship quality can also be considered as a strategic dynamic capability (Teece, 2014) which can be optimally reconfigured and deployed for achieving superior organisational outcomes. Lastly, the study provides additional empirical support towards the linking-leveraging elements of Mathews (2006a)internationalisation framework.

The findings of this study have several implications for EMNEs in general and for professional service providers in particular. Firstly, it is clear from the results that it is important to distinguish between innovation strategy and the outcome of innovation processes. This distinction is important because having an innovation stance is necessary but not sufficient in realising growth. Thus, OSPs should ensure that they have the organisational and resource 
capabilities to transform their innovation strategies into actual innovation outcomes. One such organisational resource considered in this paper is developing and maintaining effective relationships with clients and their networks. By leveraging relationship quality, OSPs from emerging economies can overcome their lack of legitimacy and capabilities to compete successfully in international markets. This finding suggests that by actively seeking and nurturing high quality relationships with clients, OSPs can gain international legitimacy by association. Second, OSPs operate across national boundaries where institutions, languages and cultures differ greatly. Investments in developing human resource capabilities such as the global mindset of top management teams should facilitate the development of strong relational capital across national and cultural boundaries. Well-developed knowledge of different cultures, languages and institutions should improve cultural sensitivities and can greatly help to overcome cultural, linguistic and institutional barriers which often hamper the development of effective client-vendor relationship (Raman et al., 2013). Thirdly, client feedback, trust, and knowledge sharing are critical for a business model based on collaborative value creation (Moeller et al., 2013) to succeed. Hence, OSPs should invest in developing a client centred organisational culture which encourages constructive client feedback without fear of reprisal and their active participation in the conceptualisation, design and delivery of innovative customised services.

As with any research, the findings of this study need to be interpreted with caution due to a number of limitations. The small size of the sample is a major limitation as it constrains the scope of the modelling exercise as well as limits the generalisation of the results. Thus, a valuable avenue for future research is to test our hypotheses using a larger sample size drawn from multiple emerging economies such as China, the Philippines and Malaysia where the IT services sector is growing rapidly. Such an exercise will increase the generalisability of the 
findings in this paper. A second limitation of the study is in its conceptualisation of the antecedent of innovation outcomes. There is a plethora of research which has used R\&D expenditure as a proxy for innovation outcome. Although R\&D expenditure do not necessarily capture IO, future research could incorporate $\mathrm{R} \& \mathrm{D}$ into a multidimensional IO construct to improve the face validity of the construct. A third research avenue relates to the use of both objective and subjective measures for the dependent variable, business growth. This approach should provide valuable insights and information into both the actual and strategic goals of OSPs. Lastly, future research could extend the present empirical model by explicitly incorporating 'learning' as an explanatory variable in explaining the internationalisation performance of service EMNEs. Such an extension will provide a more complete explanation of Mathews (2006a, 2006b) linking-leveraging-learning framework and will also contribute to the relational capital literature in explaining alliance performance (Kale et al., 2000).

The rapid growth of knowledge-intensive technology-based EMNEs such as OSPs in the last two decades is a new international business phenomenon which has brought with it new opportunities for research. Research on the conduct and performance of service EMNEs remains underdeveloped. In this paper we provide empirical support towards the 'linking' and leveraging' elements of Mathews (2006a, 2006b) LLL framework of accelerated internationalisation drawn from the experience of Indian OSPs. This research contributes to the ongoing debate on the internationalisation of EMNEs by focusing specifically on how collaborative innovation strategies based on strong client-vendor relationships have contributed to the rapid growth of OSPs from India. 
Figure 1: Collaborative value creation in the services offshoring sector

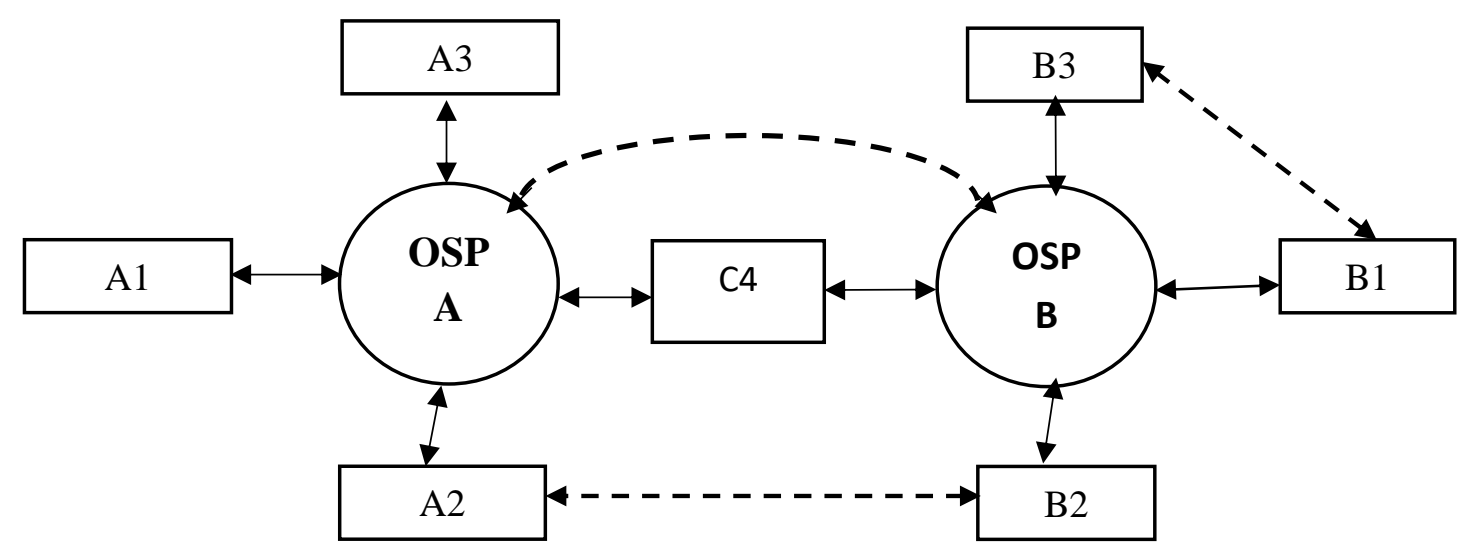


Figure 2: The conceptual model

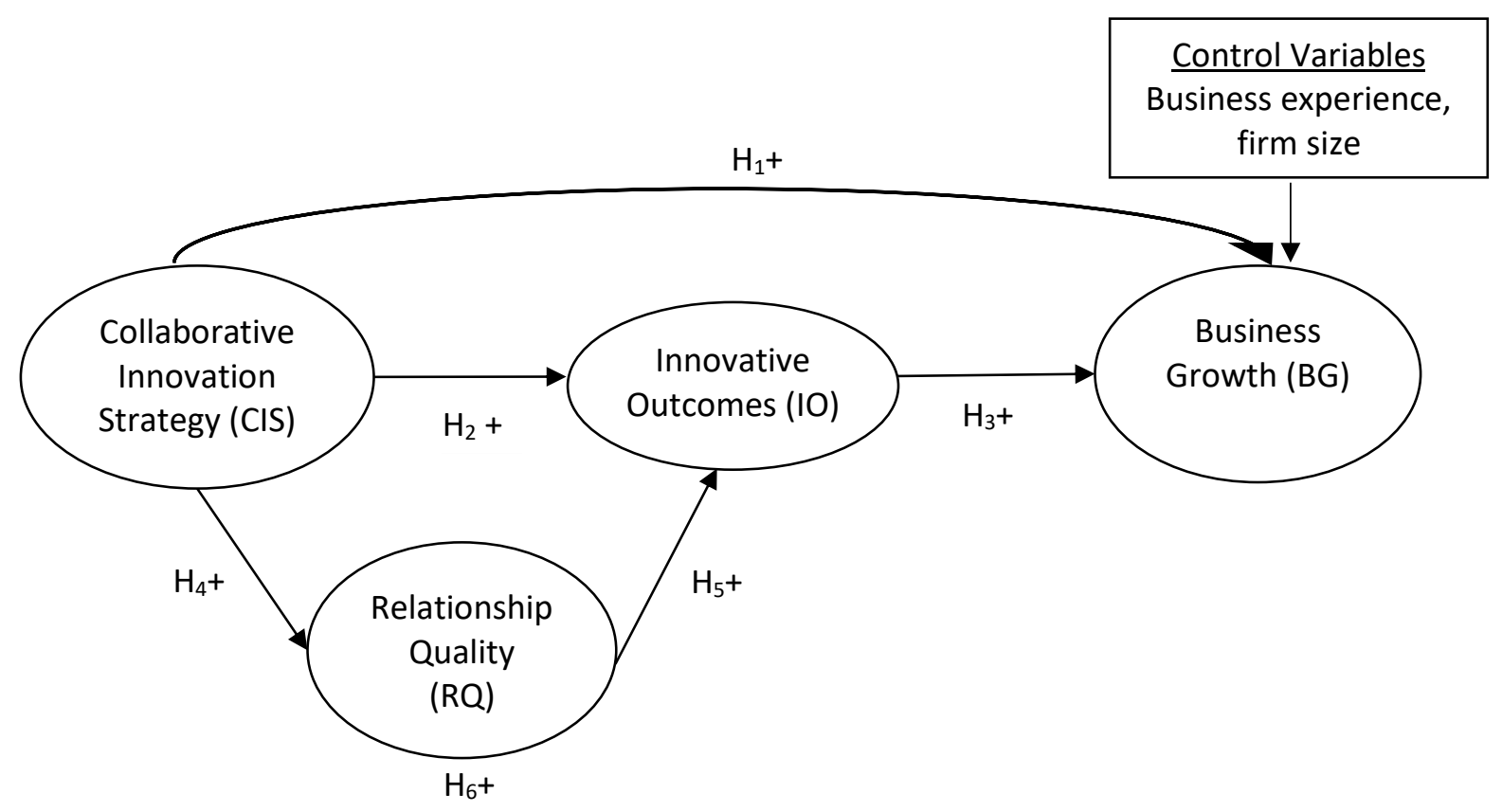


Figure 3: The structural models

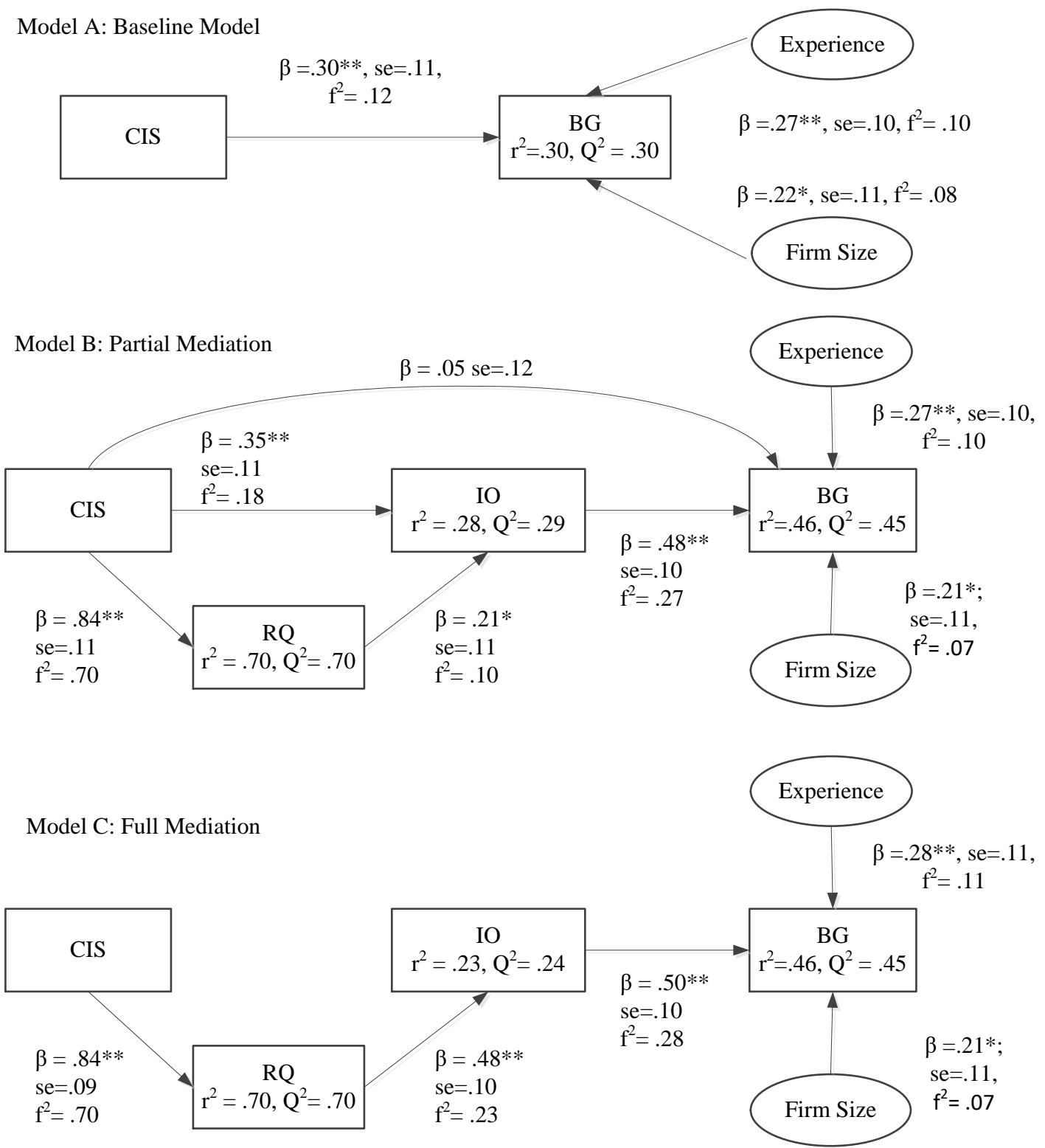

\section{Goodness of Fit Indicators:}

Average Path Coefficients (APC),

Average R-squared (ARS)

Average Variance Inflation Factor (AVIF), good if $<5$

$\begin{array}{llll} & A & B & C \\ = & .263 * * & .343 * * & .462 * * \\ = & .301 * * & .481 * * & .465 * \\ = & 1.095 & 1.722 & 1.073 \\ = & .504 & .615 & .605\end{array}$

Amato et al's (2004) Absolute Global Goodness of Fit

Legend:

$\beta=$ standardised path (beta) coefficient

$s e=$ standard error

$Q^{2}=$ Stone-Geisser $Q$-squared coefficient

$f^{2}=$ Cohen's $f$-squared $=$ effect size

$* *$ significant at $p<.01$

*significant at $p<.05$ 
Table 1: The measurement model

\section{Constructs}

Standardised factor loadings

Collaborative Innovation Strategy (CIS)

(ave $=.58 ;$ Full Collin. VIF $=2.85)$

Rate the following statements $(1=$ do not agree, ..., 5= totally agree):

This company:

Maintains strong networks for collaboration .74

Proactively involves clients in the search for new ideas

Actively involves clients in design \& delivery of customised solutions

Often uses client connections to acquire network resources

Encourages internal and external knowledge sharing and learning

$$
\begin{gathered}
\text { Innovation Outcomes }(I O) \\
\text { (ave = .89; Full Collin. VIF =1.48) }
\end{gathered}
$$

During the last 2 years, this company has: (Yes/No)

Introduced new products, services, business models

Introduced substantially improved products, services, business models

Launched 'first of its kind in the world' product \& services

$$
\begin{gathered}
\text { Relationship Quality }(R Q) \\
(\text { ave }=.62 ; \text { Full Collin. VIF }=2.89)
\end{gathered}
$$

Rate the following statements $(1=$ do not agree, $\ldots, 5=$ totally agree $)$ :

This company and its clients:

Maintain high level of trust with each other

Execute collaborative agreements and promises satisfactorily

Understand each other's business objectives and resources thoroughly

Usually resolve disputes swiftly and amicably

Provide objective feedback to each other without fear of backlash

\section{Business Growth (BG)}

(ave $=.83$; Full Collin. VIF $=1.41)$

$$
\begin{aligned}
& .85 \\
& .79 \\
& .75 \\
& .61 \\
& .61
\end{aligned}
$$

$$
\alpha=.81, C R C=.86, \rho=.87
$$

$$
\alpha=.89, C R C=.93, \rho=.94
$$

$$
\alpha=.81, C R C=.84, \rho=.85
$$

$$
\alpha=.80, C R C=.91, \rho=.91
$$

Rate the following performance statements relative to the industry average for the last 2 years $(1=$ way below industry, ..., $5=$ way above industry). 
Table 2: Mean, standard deviations and correlation coefficients

\begin{tabular}{lcccccccc}
\hline Variables & mean & SD & BG & RQ & IO & CIS & Experience & Size \\
\hline BG & 3.66 & .93 & .91 & & & & & \\
RQ & 3.64 & .45 & $.39^{* *}$ & .79 & & & & \\
IO & 2.99 & 1.65 & $.45^{* *}$ & $.47^{* *}$ & $\mathbf{. 9 4}$ & & & \\
CIS & 3.44 & .49 & $.26^{*}$ & $.67^{* *}$ & $.43^{* *}$ & $\mathbf{. 7 6}$ & & \\
Experience & 12.43 & 9.67 & $.31^{* *}$ & $.27^{*}$ & .12 & .09 & $\mathbf{1}$ & \\
Size & 4860.89 & 11196.18 & $.26^{*}$ & $.36^{* *}$ & .16 & $.34 * *$ & $.60^{* *}$ & $\mathbf{1}$ \\
\hline
\end{tabular}

Note: ** indicates significance at $p<.01 ; *$ significance at $p<.05$; bold figures are the square root values of average variance extracted (AVE) for each construct

Table 3: Direct and indirect effects of the independent variables on innovation outcomes

\begin{tabular}{ccccccc}
\hline Linkages & \multicolumn{2}{c}{ Direct effects } & \multicolumn{2}{c}{ Indirect effects } & \multicolumn{2}{c}{ Total effects } \\
\hline \multirow{2}{*}{ CIS $\rightarrow$ IO } & $\beta$ & Effect size\# & $\beta$ & Effect size\# & $\beta$ & Effect size\# \\
CIS $\rightarrow$ RQ $\rightarrow$ IO & $.35^{* *}$ & .18 & none & none & $.35^{* *}$ & .18 \\
& $.35^{* *}$ & .18 & $.18^{* *}$ & .09 & $.53^{* *}$ & .27 \\
\hline
\end{tabular}

Note: $\beta$ indicates path (beta) coefficient; \# Cohen's $f^{2}$ (Cohen, 1992); * significance at $p<.05$ 


\section{Reference List}

Adler, P. S. 2002. Market, heirarchy, and trust: The knowledge economy and the future of capitalism. In Choo, C. W., \& Bontis, N. (Eds.), The Strategic Management of Intellectual Capital and Organizational Knowledge. Oxford: Oxford University Press.

Amato, S., Esposito-Vinzi, V., \& Tenenhaus, M. 2004. A global goodness-of-fit index for PLS structural equation modelling. Oral Communication to PLS Club. France: HEC School of management.

Anderson, J., \& Gerbing, D. W. 1988. Structural equations modelling in practice: A review and recommended two step approach. Psychological bulletin, 103(3): 411-423.

Ayuso, S., Rodriguez, M., Garcia-Castro, R., \& Arino, M. 2011. Does stakeholder engagement promote sustainable innovation orientation. Industrial Management and Data Systems, 111(9): 1399-1417.

Bagozzi, R., Yi, Y., \& Phillips, L. 1991. Assesing construct validity in organisatioal research. Administration Science Quarterly, 36(3): 421-458.

Barney, J. B. 1991. Firm resources and sustained competitive advantage. Journal of Management, 17(1): 99-120.

Barthelemy, J. 2003. The hard and soft sides of IT outsourcing management. European Management Journal, 21(5): 539-548.

Bartlett, C., \& Ghoshal, S. 2000. Going global: Lessons from late movers. Harvard Business Review, April: 75-86.

Bowen, F. E., Rostami, M., \& Steel, P. 2010. Timing is everything: A meta-analysis of the relationships between organizational performance and innovation. Journal of Business Research, 63(11): 1179-1185.

Cardoza, G., \& Fornes, G. 2011. The internationalisation of SMEs from China: The case of Ningxia Hui Autonomous Region. Asia Pacific Journal of Management, 28(4): 737-759.

Chadee, D., \& Mattson, J. 1998. Do service and merchandise exporters behave and perform diffrently? A New Zealand investigation. European Journal of Marketing, 32(9/10): 830-842.

Chittoor, R., Sarkar, M. B., Ray, S., \& Aulakh, P. S. 2009. Third-World copycats to emerging multinationals: Institutional changes and organizational transformation in the Indian pharmaceutical industry. Organization Science, 20(1): 187-205.

Cohen, J. 1992. A power primer. Psychological bulletin, 112(1): 155-159.

Conte, A., \& Vivarelli, M. 2013. Succeeding in innovation: Key insights on the role of R\&D and technological acquisition drawn from company data. Discussion Paper No 7671, Institute for the Study of Labour, Germany.

Crossan, M. M., \& Apaydin, M. 2010. A multi-dimensional framework of organizational innovation: A systematic review of the literature. Journal of Management Studies, 47(6): 1154-1191.

Cuervo-Cazurra, A. 2016. Multilatinas as sources of new research insights: The learning and escape drivers of international expansion. Journal of Business Research, 69: 1963-1972.

Damanpour, F., \& Aravind, D. 2011. Managerial innovation: Conceptions, processes, and antesedents. Management \& Organization Review, 8(2): 423-454.

DeVellis, R. 2012. Scale Development: Theory and Applications. Thousand Oaks, USA: Sage.

Elango, B., \& Pattnaik, C. 2007. Building capabilities for international operations through networks: A study of Indian firms. Journal of International Business Studies, 38(4): 541-555.

Franke, N., \& Schreier, M. 2010. Why customers value self-designed products: The importance of process effort and enjoyment. Journal of Product Innovation Management, 27(7): 1020-1031. 
Gaur, A. S., Kumar, V., \& Singh, D. 2014. Institutions, resources, and internationalization of emerging economy firms. Journal of World Business, 49(1): 12-20.

Geisser, S. 1975. The predictive sample reuse method with applications. Journal of the American Statistical Association, 70(350): 320-328.

Hair, J. F., Black, W. C., Babin, B. J., \& Anderson, R. E. 2010. Multivariate Data Analysis: A Global Perspective. New Jersey: Pearson.

Hao, T., \& Mathews, J. A. 2015. Accelerated internationalization and resource leverage strategizing: The case of Chinese wind turbine manufacturers. Journal of World Business, 50(3): 417-427.

Harman, H. H. 1976. Modern Factor Analysis. Chicago IL: University of Chicago.

Hennart, J.-F. 2012. Emerging market multinationals and the theory of the multinational enterprise. Global Strategy Journal, 2(3): 168-187.

Holtzman, Y. 2014. A strategy of innovation through the development of a portfolio of innovation capabilities. Journal of Management Development, 33(1): 24-31.

Holzweber, M., Mattsson, J., Chadee, D., \& Raman, R. 2012. How dynamic capabilities drive performance in the Indian IT industry: The role of information and co-ordination. Service Industries Journal, 32(4): 531-550.

Infosys. 2014. Annual report 2014: Evolving with changing times. http://www.infosys.com/investors/reports-filings/annual-report/annual/Documents/Infosys-AR14.pdf Accessed March 26, 2014.

Johanson, J., \& Vahlne, J.-E. 2011. Markets as networks: Implications for strategy-making. Journal of the Academy of Marketing Science, 39(4): 484-491.

Kale, P., Singh, H., \& Permutter, H. 2000. Learning and protection of proprietary assets in strategic alliances: Building relational capital. Strategic Management Journal, 21(3): 217-237.

Kock, N. 2012. WarpPLS3.0 User Manual. Laredo, Texas: Script Warp Systems.

Kühne, B., Gellynck, X., \& Weaver, R. D. 2013. The influence of relationship quality on the innovation capacity in traditional food chains. Supply Chain Management, 18(1): 52-65.

Kumar, K., Boesso, G., Favotto, F., \& Menini, A. 2012. Strategic orientation, innovation patterns and performance of SMEs and large companies. Journal of Small Business and Enterprise Development, 19(1): 132-145.

Kumar, V., Mudambi, R., \& Gray, S. 2013. Internationalization, innovation and institutions: The 3 I's underpinning the competitiveness of emerging market firms. Journal of International Management, 19(3): 203-206.

Lahiri, S., \& Kedia, B. 2009. The effects of internal resources and partnership quality on firm performance: An examination of Indian BPO providers. Journal of International Management, 15(2): 209-224.

Lahiri, S., \& Kedia, B. L. 2011. Determining quality of business-to-business relationships: A study of Indian IT-enabled service providers. European Management Journal, 29(1): 11-24.

Lee, J.-N. 2001. The impact of knowledge sharing, organizational capability and partnership quality on IS outsourcing success. Information \& Management, 38(5): 323-335.

Leiponen, A. 2012. The benefits of R\&D and breadth in innovation strategies: A comparison of Finnish service and manufacturing firms. Industrial \& Corporate Change, 21(5): 1255-1281.

Lewin, A., Massini, S., \& Peeters, C. 2009. Why are companies offshoring innovation? The emerging global race for talent. Journal of International Business Studies, 40(6): 901-925.

Lindell, M. L., \& Whitney, D. 2001. Accounting for common method variance in cross sectional research designs. Journal of applied psychology, 86(1): 114-121. 
Madhok, A., \& Keyhani, M. 2012. Acquisitions as entrepreneurship: asymmetries, opportunities, and the internationalization of multinationals from emerging economies. Global Strategy Journal, 2(1): 26-40.

Malhotra, N. K., Kim, S. S., \& Patil, A. 2006. Common method variance in IS research: A comparison of alternative approaches and a reanalysis of past research. Management Science, 52(12): 1865-1883.

Marcoulides, G. A., \& Saunders, C. 2006. PLS: A silver bullet? MIS quarterly, 30(2): 3-9.

Mathews, J. 2006a. Dragon multinationals: New players in 21st century globalization. Asia Pacific Journal of Management, 23(1): 5-27.

Mathews, J. A. 2006b. Response to Professors Dunning and Narula. Asia Pacific Journal of Management, 23(2): 153-155.

McManus, J. T., Li, M., \& Moitra, M. 2007. China and India: Opprtunities and threatfor the global software industry. London: Elsevier.

Melia, M., Perez, A., \& Dobon, S. 2010. The influence of innovation orientation on the internationalisation of SMEs in the service sector. The Service Industries Journal, 30(5): $777-$ 791.

Meyer, K., \& Thaijongrak, O. 2013. The dynamics of emerging economy MNEs: How the internationalization process model can guide future research. Asia Pacific Journal of Management, 30(4): 1125-1153.

Moeller, S., Ciuchita, R., Mahr, D., Odekerken-Schroder, G., \& Fassnacht, M. 2013. Uncovering collaborative value creation patterns and establishing corresponding customer roles. Journal of Services Research, 16(4): 471-487.

Nandakumar, M. K., Purkayastha, S., \& Kumar, V. 2016. Guest Editors' Introduction. International Studies of Management \& Organization, 46(1): 1-7.

Nasscom. 2010. Annual Report 2009-2010. New Delhi: National Association of Software and Service Companies

Nasscom. 2013. The IT-BPO secor in India: Strategic review. New Delhi: National Association of Software and Service Comapnies.

Nasscom. 2015. Annual Report 2014-15. New Delhi: National Association of Software and Service Comapnies.

OECD. 2005. Oslo manual: Guidelines for collecting and interpreting innovation data. Peris: OECD and European Commission.

Peng, M. W., Sunny Li, S., Pinkham, B., \& Hao, C. 2009. The institution-based view as a third leg for a strategy tripod. Academy of Management Perspectives, 23(3): 63-81.

Preacher, K. J., \& Hayes, A. F. 2008. Asymptotic and resampling strategies for assessing and comparing indirect effects in multiple mediator models. Behavioural Research Methods, 40(3): 879-891.

Pulos, \& Rogness. 1995. Soft modelling and special education. Remedial and Special Education, 16(3): 184-192.

Ramachandran, J., \& Pant, A. 2010. The liability of origin: An emerging economy perspective on the costs of doing business abroad. In Divinney, T. M., Pedersen, T., \& Tihanyi, L. (Eds.), Advances in International Management: The Past, Present and Future of International Business and Management: 1 - 58. New York: Emerald.

Ramamurti, R. 2012. What is really different about emerging market multinationals? Global Strategy Journal, 2(1): 41-47.

Raman, R., \& Chadee, D. 2011. A comparative assessment of the information technology services sector in India and China. Journal of Contemporary Asia, 41(3): 453-470. 
Raman, R., Chadee, D., Roxas, B., \& Michailova, S. 2013. Effects of partnership quality, talent management, and global mindset on performance of offshore IT service providers in India. Journal of International Management, 19(4): 333-346.

Roy, A., \& Berger, P. D. 2005. E-mail and mixed mode database surveys revisited: exploratory analyses of factors affecting response rates. Journal of Database Marketing \& Customer Strategy Management, 12(2): 153-171.

Roy, S., Sivakumar, K., \& Wilkinson, I. F. 2004. Innovation generation in supply chain relationships: A conceptual model and research propositions. Journal of the Academy of Marketing Science, 32(1): 61-79.

Sauvant, K. P., Maschek, W. A., \& McAllister, G. 2009. Foreign direct investment by emerging market multinational enterprises, the impact of financial crisis and recession and challenges ahead. Global Forum on International Investment, 7(4): 397-410.

Sethi, A., \& Gott, J. 2016. A. T. Kearney Global Services Location Index. A. T. Kearney Inc.

Slater, S., Olson, E., \& Hult, G. T. 2006. The moderating influence of strategic orientation on the strategy formation capability-performance relationship. Strategic Management Journal, 27: 1221-1231.

Stone, M. 1974. Cross-validatory choice and assessment of statistical predictions. Journal of the Royal Statistical Society, 36(1): 111-147.

Stuart, T. E., Hoang, H., \& Hybels, R. C. 1999. Interorganizational endorsements and the performance of enterpreneurial ventures. Administrative Science Quarterly, 44(2): 315-349.

Teece, D. J. 2014. A dynamic capabilities-based entrepreneurial theory of the multinational enterprise. Journal of International Business Studies, 45(1): 8-37.

Thite, M., Wilkinson, A., Budhwar, P., \& Mathews, J. A. 2016. Internationalization of emerging Indian multinationals: Linkage, leverage and learning (LLL) perspective. International Business Review, 25(1, Part B): 435-443.

UNCTAD. 2014. World Investment Report 2014: Investing in the SDGs - An Action Plan. New York.

Vargo, S. L. 2008. Customer integration and value creation: Paradigmatic traps and perspectives. Journal of Service Research, 11(2): 211-215.

Vargo, S. L., \& Lusch, R. F. 2004. Evolving a new dominant logic for marketing. Journal of Marketing, 68(1): 1-17.

Wetzels, M., Odekerken-Schröder, G., \& van Oppen, C. 2009. Using PLS path modelling for assessing hierarchical construct models: guidelines and empirical illustration. MIS quarterly, 33(1): 177-195.

Zaheer, S. 1995. Overcoming the liability of foreignness. Academy of Management Journal, 38(2): 341-363.

Zeithaml, V., Parasuraman, A., \& Berry, L. L. 1985. Problems and strategies in services marketing. Journal of Marketing, 49(2): 33-46. 